\title{
Nutritional effects of autoxidized fats in animal diets
}

\section{3.* The growth of turkeys on diets containing oxidized fish oil $\dagger$}

\author{
BY C. H. LEA AND L. J. PARR \\ Low Temperature Research Station, Cambridge \\ AND J. L. L'ESTRANGE AND K. J. CARPEN'TER \\ School of Agriculture, University of Cambridge

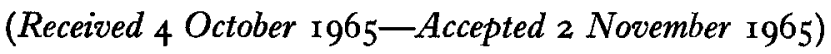

\begin{abstract}
I. Turkey poults were fed from day-old to 6 weeks on a practical-type diet containing $10 \%$ white fish meal (supplying $0.7 \%$ lipid) and other constituents, mainly cereals (supplying $3.3 \%$ lipid), together with either $1.5 \%$ of anchovy oil that had been allowed to autoxidize under various conditions or $1.5 \%$ of fresh beef fat. 2. For group I the whole diet with anchovy oil was stored in air at $15^{\circ}$ for 3 months before feeding. Its lipid oxidized only slowly, with no appreciable rise in peroxide value and little destruction of its polyunsaturated fatty acids. For groups 2 and 3 the anchovy oil was mixed with the white fish meal, and the mixture was stored for 3 months, by which time most of its polyunsaturated fatty acids had been destroyed by autoxidation and the pv of the extractable lipid, after reaching a peak of $260 \mu \mathrm{moles} / \mathrm{g}$, had fallen again to 110 . At this point the anchovy oil-fish meal premixture was further mixed with the basal diet and used, either immediately (group 2) or after 3 months' further storage (group 3). 3. The turkeys in all three groups receiving 'fish oil' remained healthy and grew well, with only slightly apparent (and not significantly) lower weight gains than those on the control diet. There was no significant treatment effect on liver weight, serum aspartate aminotransferase or serum alanine aminotransferase activity. All the birds stored vitamin $A$ in their livers, though the diets had provided not more than adequate supplies of this vitamin, but the reserves accumulated were significantly lower when the diets contained oxidized fat. On roasting, the turkeys of group I had a definite and objectionable fishy flavour, whereas those of groups 2 and 3 were as palatable as the controls on the beef fat diet.
\end{abstract}

In previous papers of this series it has been shown that the inclusion of $5 \%$ of beef fat autoxidized to the comparatively high peroxide value (pv) of roo $\mu$ moles $/ g$ (200 m-equiv. $/ \mathrm{kg}$ ) in a well-balanced diet had only marginal effects on the performance of rats (Lea, Parr, L'Estrange \& Carpenter, I964) or chicks (L'Estrange, Carpenter, Lea \& Parr, I966) and apparently none of practical significance. Health, weight increase and food conversion were all satisfactory on diets that provided normal levels of fat-soluble vitamins in stabilized form.

In animal rations, apart from fat added as such, nearly all the ingredients have a certain lipid content, and disorders in practical feeding have been attributed on different occasions to the oxidation of fat in cereals, fish meals and meat meals (cf. Carpenter, L'Estrange \& Lea, 1966). Fish oil was chosen as the subject for the investigation reported here.

When fish meal is manufactured from 'oily' fish, most of the oil is removed by

* Paper no. 2: Br. F. Nutr. (1966), 20, II3.

+ Some of these results have been communicated in a preliminary form (L'Estrange, Carpenter, Lea $\&$ Parr, r965). 
pressing, but the amount remaining may be from 6 to $16 \%$ of the product. In commercial practice there have been doubts about the safety of using oily fish meals for young stock, even at the lower end of this range, if the pv of the extractable lipid was above certain limits.

Fish oil is much more unsaturated than beef fat and much more unstable. There have been reports of adverse nutritional effects in rats (Rasheed, Oldfield, Kaufmes \& Sinnhuber, 1963) and pigs (Oldfield, Sinnhuber \& Rasheed, 1963) given 10\% of fish oil of low pv. Even fresh clay-bleached oil amounting to $15 \%$ of the diet was found to be toxic to rats, apparently owing to its rapid autoxidation in the synthetic diet during exposure in the feeding pans before consumption (Rasheed et al. 1963). On the other hand, Laksesvela (1961) and March, Biely, Claggett \& Tarr (1962) both added $10 \%$ of lipids, extracted from herring meal that had been allowed to oxidize for many months, to balanced chick diets and found no deleterious effect; Carpenter, Lea \& Parr ( $199_{3} 3$ ) showed that the slightly lower nutritional value of a fish meal of high fat content allowed to oxidize for a year could not be explained by any depressant effect of the extractable lipid itself on weight increase.

There have been suggestions from members of the feed-compounding industry that oxidized fish oil might be particularly dangerous for young livestock if it was stored in the whole diet for some months before feeding. It has already been shown (Lea et al. 1964; L'Estrange et al. 1966) that, after the addition of $5 \%$ beef fat of a high pv, but containing $0.02 \%$ BHT (2,6-di-t-butyl-4-methyl-phenol), to a practical poultry ration, there was no further oxidation of the total extractable lipids of the mixture during storage in air at room temperature and that the pv decreased fairly rapidly. It was thought, however, that oxidation might not cease in the same way after the addition to a similar ration of an oxidized fish meal of high fat content to which no antioxidant had been added.

We therefore decided to investigate $(a)$ the chemical changes occurring during storage in air at room temperature of a complete diet containing $11.5 \%$ of either a fresh or a highly oxidized oily fish meal, and $(b)$ the effects on the performance of young turkeys of both these diets after storage for 3 months, as well as of a similar diet in which the highly oxidized fish meal was mixed with the rest of the diet each day before feeding. To simulate fresh oily fish meal, which was not obtainable, $I \cdot 5$ parts of fresh anchovy oil were added to Io parts of white fish meal, so as to give the final diet a fish oil content of $2 \cdot 2 \%$. There seemed little point for our purpose in using the high level of fish oil given by Rasheed et al. (1963) and Oldfield et al. (1963), since such oils as components of fish meals are normally present in mixed diets only at levels below $1 \cdot 5 \%$, and even with the level of $2 \cdot 2 \%$ total fish oil used in our experiment definite fishy taints were already present in the roasted meat.

As a control in the feeding trial, beef fat replaced the anchovy oil, and this mixture, kept fresh under nitrogen at $-20^{\circ}$, was mixed with the rest of the diet daily before feeding.

Turkeys were chosen as experimental animals because they are believed to be particularly susceptible to damage from the ingestion of oxidized fat. Moreover, it has been shown that turkeys transfer a smaller proportion of dietary tocopherol to their 
body tissues than do chickens and that their fat is more susceptible to the development of oxidative rancidity (Mecchi, Pool, Behman, Hamachi \& Klose, 1956).

Briefly, birds receiving $2 \cdot 2 \%$ fish oil ranging in pv from I Io down to $60 \mu$ moles $/ \mathrm{g}$ remained healthy; the weight gains recorded were not significantly lower than those obtained on fresh fish oil or beef fat.

\section{EXPERIMENTAL}

Each of four diets was given to seven female Broad Breasted White turkeys from day-old to 6 weeks, in each of three cages, the food, in meal form, being always available. After the final weighing the birds were killed at a poultry-packing station, examined for evidence of disease or abnormality, and the livers removed for analysis. The carcasses were used for palatability tests.

\section{Diets}

Each of the four experimental diets contained 88.5 parts of a common basal mixture designed to be 'practical' in the sense that all the vitamins were present in adequate but not extravagant quantities. This was mixed with I 15 parts of oily fish meal, prepared by premixing 1.5 parts of oil or fat with ro parts of fresh white fish meal.

Basal diet. The basal diet consisted of: ground wheat $10.75 \%$, finely ground barley $14.9 \%$, maize meal $24.9 \%$, extracted soya meal $27.8 \%$, unextracted dried yeast $5.0 \%$ and a premix containing minerals, vitamins and antibiotics $5.15 \%$. The premix contributed to the final diet: vitamin E (as Rovimix E, ro \% DL- $\alpha$-tocopheryl acetate; Roche Products Ltd, Welwyn Garden City) ${ }_{3}$ i.u./kg; vitamin A (as Rovimix A 50 ; Roche Products Ltd) 7700 i.u. $/ \mathrm{kg}$; vitamin D (as Rovimix $\mathrm{D}_{3}-100$; Roche Products Ltd) I900 i.u./kg; menaphthone $\mathrm{I}^{\cdot} 3 \mathrm{ppm}$; riboflavine $5^{\cdot} \mathrm{I} 5 \mathrm{ppm}$; calcium pantothenate $\mathrm{I} 3 \mathrm{ppm}$; manganese (as $\mathrm{MnSO}_{4} \cdot \mathrm{H}_{2} \mathrm{O}$ ) $88 \mathrm{ppm}$; zinc (as zinc chloride) $7 \mathrm{I} \mathrm{ppm}$; sulphaquinoxaline (as Embazin premix; May \& Baker Ltd, Dagenham, Essex) I60 ppm; dimetridazole (as Emtryl premix; May \& Baker Ltd) I6o ppm; oxytetracycline (as Terramycin; Pfizer Ltd, Sandwich, Kent) $8.9 \mathrm{ppm}$.

The four experimental diets were prepared and offered as described below.

Diet no. I. Fresh oily fish meal (see p. I24) was prepared by mixing I.5 parts fresh anchovy oil with ro parts fresh white fish meal and then mixed with basal diet and the whole stored in loose polythene bags (opened at intervals to ensure a free supply of oxygen) at $15^{\circ}$ for 3 months, after which feeding was begun.

Diet no. 2. Oxidized oily fish meal was mixed with the basal diet daily before feeding. The oxidized fish meal had been prepared by mixing 1.5 parts anchovy oil with Io parts fresh white fish meal and holding for 3 months at $15^{\circ}$ in air.

Diet no. 3. Oxidized oily fish meal, prepared as above, was mixed with the basal diet, the whole being stored for a further 3 months in air at $15^{\circ}$ before feeding began (and during the 6 weeks of the trial).

Diet no. 4. As control, fresh beef fat and fresh white fish meal were mixed and stored under nitrogen at $-20^{\circ}$. A mixture of this material and the basal diet was made up daily for feeding. 
Each diet contained $27.6 \%$ crude protein. Part of the bulk of basal diet made up for diets $\mathrm{I}$ and 3 was held at $0^{\circ}$ (to minimize change) during the period for which these diets were being stored before feeding. It was then used to prepare diets 2 and 4 . Apart from an increase in apparent free fatty acidity from 22 to $29 \%$ over 132 days, analysis indicated no appreciable change in the lipid constituents of the material during this time; the pv increased by only $0.9 \mu \mathrm{moles} / \mathrm{g}$ and there was no fall in iodine value (fatty acid basis).

\section{Fats used}

Beef fat. Fresh beef adipose tissue (brisket) was dry-rendered in the laboratory, with precautions against oxidation. It had a pv of zero.

Anchovy oil. A sample of Peruvian anchovy oil was purified by treatment with silicic acid and alumina and filtered. So treated, it gave too stable an oily fish meal for our purpose, and it was therefore allowed to autoxidize to a $\mathrm{pv}$ of $15 \mu \mathrm{moles} / \mathrm{g}$ before mixing ( ${ }^{\circ} 5$ parts) with white fish meal (Io parts). The iodine value of the oil was 184 . The white fish meal contained $7 \cdot 3 \%$ lipid of iodine value 152 and $\mathrm{pv} 7 \cdot 7 \mu \mathrm{moles} / \mathrm{g}$.

\section{Changes in the diets during storage}

Absorption of oxygen. The moisture content of the prepared oily fish meals was $6.4 \%$ and their equilibrium relative humidities, as determined by measurement of weight gain or loss in a range of atmospheres of controlled moisture contents, were $45 \%$ of saturation. The corresponding values for the mixed diets were $12 \cdot$ I $\%$ moisture and $60 \%$ of saturation. The rates of absorption of oxygen by these materials during storage at $15^{\circ}$ were therefore measured by holding samples at this temperature in flasks filled with air, fitted with mercury manometers and containing $\mathrm{CO}_{2}$-absorption tubes with $\mathrm{KOH}$ solutions of a concentration calculated to maintain the moisture contents unchanged.

Extraction and examination of the lipids. At suitable intervals during storage, lipid was recovered from the several diets by extraction with chloroform-methanol (4:I, $\mathrm{v} / \mathrm{v}$ ) and examined for peroxide and carbonyl group contents and also for the iodine values of the fatty acids recovered after saponification, all by methods previously described (Lea et al. 1964). Some determinations of carbonyl content were also made after reduction of interfering peroxides (Täufel \& Linow, 1964; Lea \& HobsonFrohock, 1965).

\section{Performance of the birds and examination of the carcasses}

Weight increase and food consumption were measured throughout the experiment; at the end, the livers were weighed and their vitamin A contents determined as previously described (Lea et al. 1964). Blood samples were taken at slaughter and levels of serum aspartate aminotransferase (Asp.T), previously known as glutamicoxaloacetic transaminase (GOT), and of serum alanine aminotransferase (Al.T), previously known as glutamic-pyruvic transaminase (GPT), were determined on individual samples, using procedures and reagents of the Sigma Chemical Company (1964). The activities of the enzymes were converted from the units of Sigma- 
Frankel into the International Unit ( $\mu$ moles of product formed per min, per l. of serum at $25^{\circ}$ ) by multiplying by 0.483 (cf Boyd, Douglas, Gould \& Grimes, I964).

\section{Flavour of the cooked meat}

The birds were roasted and the cooked meats, combined in their four groups, were tasted and ranked in order of preference by a panel of nine to twelve (usually ten) persons, as previously described (L'Estrange et al. 1966). Leg and breast meats were tasted separately, both before and after reheating, and the whole procedure was carried out twice.

\section{RESULTS}

\section{Changes in the diets during storage}

Absorption of oxygen. As already mentioned, purified anchovy oil when mixed with white fish meal in the proportion of 1.5 parts to Io parts proved too resistant to oxidation to be legitimately compared with a commercial oily fish meal. The oil was therefore pre-oxidized to a pv of $15 \mu$ moles/g before mixing with the white fish meal, and the product then absorbed oxygen on storage at $15^{\circ}$, as shown for diet 3 in Fig. I.

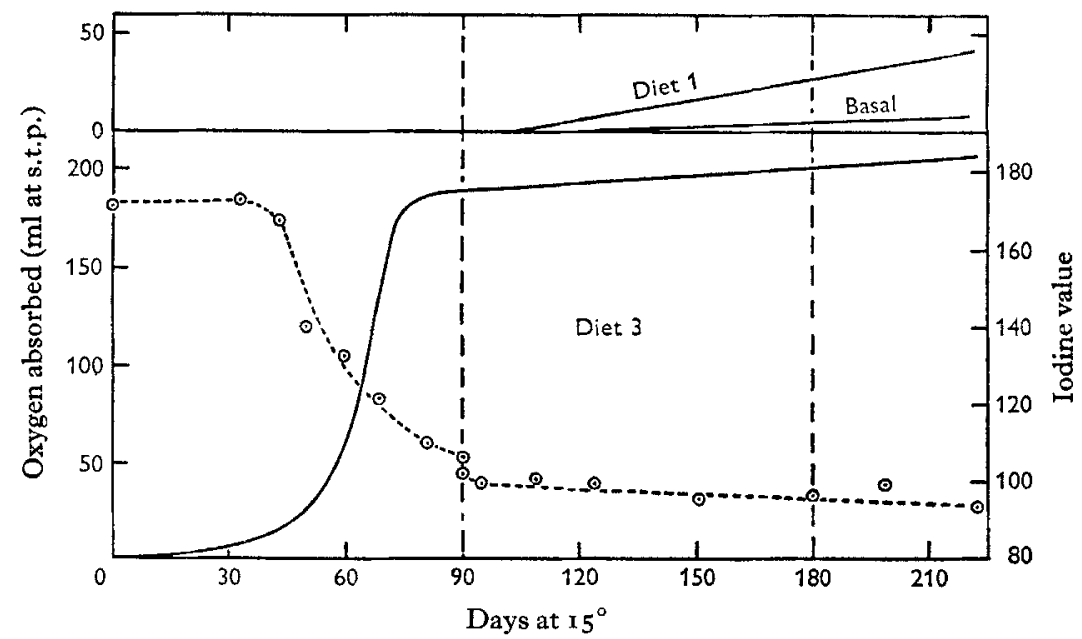

Fig. 1. Absorption of oxygen by the diets (-) and changes in iodine value of lipid constituents (- - -). The last 42 days cover the feeding period. In diet 3 the first 90 days represent storage of the oily fish meal alone (diet 2 was prepared similarly) and the remainder of the time storage of the complete diet. The basal diet was not given alone. The results relate to $\mathrm{I} \mathrm{I}^{\circ} 5 \mathrm{~g}$ oily fish meal, $88.5 \mathrm{~g}$ basal diet or $100 \mathrm{~g}$ complete diet and are directly comparable.

A marked induction period was succeeded by a period of rapid oxygen absorption, which was already over when, after 90 days, the oxidized oily fish meal was first mixed with the basal diet to form diet no. 2. During the second period of 90 days storage in the preparation of diet 3 (Fig. I) and during the feeding period there was little further uptake of oxygen by the complete diet.

The basal diet itself absorbed oxygen only slowly; when the freshly prepared oily fish meal was mixed with it to form diet no. I oxygen absorption was still rather slow. 
However, some oxidation did occur during storage of this diet, as indicated by the absorption of oxygen recorded (Fig. I) and confirmed by a fall in iodine value of about 5 units on the total lipid basis, equivalent to about 12 units on the fish lipid basis.

Changes in the lipids. The basal diet contained $3.7 \%$ lipid of iodine value 100 and pv $3.7 \mu \mathrm{moles} / \mathrm{g}$. The initial characteristics of the anchovy oil and of the white fish meal with which it was mixed have already been given (p. 126). The basal diet therefore contributed $3.3 \%$ lipid, the white fish meal $0.7 \%$ and the added anchovy oil or beef fat $\mathrm{I} \cdot 5 \%$, making a total lipid content for all diets of $5.5 \%$.

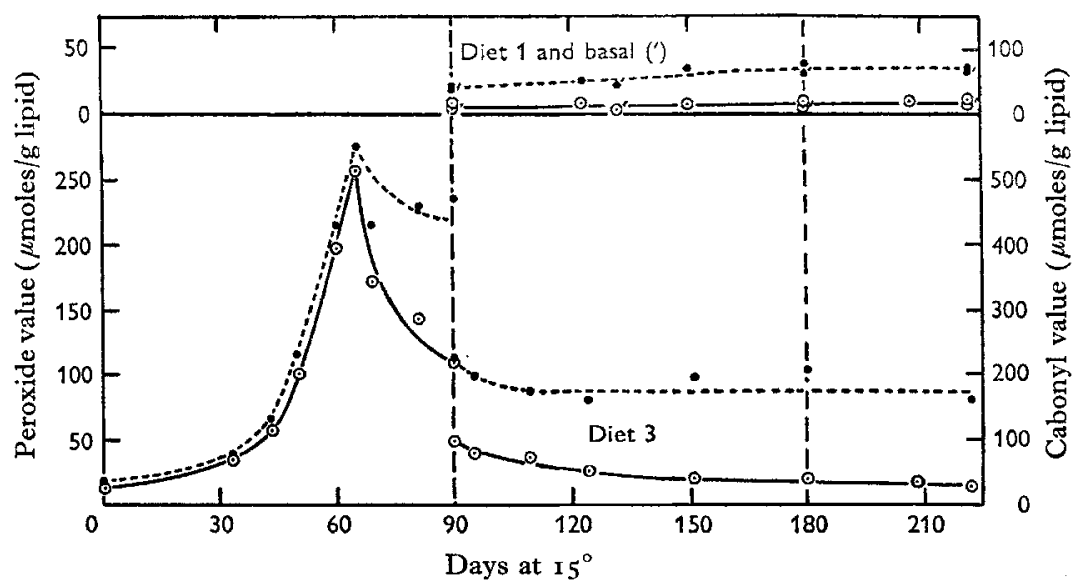

Fig. 2. Chemical changes in the lipid constituents of the diets during storage; _-; peroxide value; - . - carbonyl value. Other details as for Fig. I.

Changes in the pv and carbonyl value as recorded on samples of lipid extracted from the diets during the experiment are given in Fig. 2, and changes in iodine value in Fig. I. Since the first part of the preparation of diet no. 2 was a repetition of the procedure already followed for diet no. 3 , the white fish meal-anchovy oil mix having been held meanwhile under nitrogen at $-20^{\circ}$, only a few confirmatory analyses were done on this diet.

Peroxide and carbonyl values. Though a high pv provides unequivocal evidence of lipid oxidation, a low pv is not proof that oxidation has not occurred. For this reason, the determination of carbonyl groups, which is less open to this criticism, is perhaps the better criterion of lipid oxidation.

In the anchovy oil-white fish meal system (diets 2 and 3 , first 90 days) both peroxide and carbonyl values by direct determination, after an initial lag phase, rose rapidly together (Fig. 2). After reaching maximum values at $6_{5}$ days both fell, the pv the more rapidly. After mixing, the pv of the lipid extractable from diet 3 continued to fall slowly, but the carbonyl value remained almost constant.

Since peroxides react to some extent as carbonyls in the chemical determination of carbonyls by the 2,4-dinitrophenylhydrazine method used, it is obviously desirable to destroy the peroxides first; this can be done conveniently by reduction with potassium iodide and glacial acetic acid, as in the pv determination. However, the method, already troublesome owing to the necessity for careful purification of the solvents 
used, becomes more tedious and reproducibility is rather poor, so that determinations are preferably carried out in triplicate.

Whereas the pv of the lipid in the anchovy oil-white fish meal mixture fell from its peak of 260 down to i 10 $\mu$ moles/g, the carbonyl value after reduction fell only from 340 to $310 \mu$ moles $/ \mathrm{g}$. It would seem, therefore, that determination of the carbonyl values after reduction of interfering peroxides has some advantages over that of the pv as a measure of lipid oxidation. Its greater complexity and poorer reproducibility, and the possibility of interference by non-lipid constituents of mixed diets, tend to militate against its adoption as a practical method for routine use.

FDNB-available lysine. In the fresh oily fish meal the FDNB-available lysine content was $6.6 \mathrm{~g} / \mathrm{r} 6 \mathrm{~g} \mathrm{~N}$ and in the corresponding material stored for 3 months in air it was $5.8 \mathrm{~g} / 16 \mathrm{~g} \mathrm{~N}$.

\section{Performance of the birds}

Of the eighty-four birds in the experiment, two became unwell and were removed. The first, killed at 14 days, was found to have received a spinal injury, and the second, killed at 24 days, had an injured wing.

The remaining birds appeared healthy, showed good appetite and grew well, with the results summarized in Table I. The mean rates of gain on diets 2 and 3 , containing oxidized fish oil, were, for each, $6 \%$ less than that of the control groups receiving fresh beef fat (diet no. 4), but these differences were not statistically significant. The performance of the groups receiving fresh anchovy oil was intermediate. Slight apparent differences in food consumption were in the same direction, but were also not significant, mean feed conversions for the diets being all within $3 \%$ (Table r). On examination post mortem, seven birds showed evidence of some chronic respiratory infection (one on diet no. I, two on diet no. 2, none on diet no. 3 and three on diet no. 4), but the average weight of these birds was high. All the livers appeared normal.

All the turkeys showed net increases in their liver stores of vitamin A, from day-old values of 230 i.u./liver, but the quantities stored with diets 2 and 3 , containing oxidized fish oil, were significantly lower than those for the control diet containing fresh beef fat; the value with the diet containing fresh fish oil was intermediate. There was no significant difference in liver weights between treatments. The levels of Asp.T were highest on diet $\mathrm{x}$, and lowest on diet 4, with intermediate levels on diets 2 and 3; however, these differences were not significant. There was also no significant treatment effect on levels of Al.T.

\section{Flavour of the cooked meat}

The results of the eight tests by the tasting panel are summarized in Table 2. Though most of the tasters had had previous panel experience, no training was given for this project, and the first test was less satisfactory than subsequent ones. One panel member consistently distinguished the meat produced on diet no. I, but preferred its stronger flavour (which he did not recognize as fishy) to that of the milderflavoured control, and his results have been excluded from the panel averages. All other tasters consistently condemned the meat from diet no. I as obviously fishy.

A minority of tasters occasionally marked samples 2 and 3, particularly the leg 
meat, which had a higher lipid content than the breast, as 'very slightly fishy', and others found that these samples had a slightly stronger, but not fishy or unpleasant, flavour than the control. The average scores, however, indicate that there was little to choose in acceptability between these samples under panel conditions and therefore nothing likely to be of practical significance. There was no apparent accentuation of fishy flavour on reheating.

\section{Table I. Details of treatments and mean performance of turkeys in each treatment in the feeding trial}

\begin{tabular}{|c|c|c|c|c|c|}
\hline & Diet I & Diet 2 & Diet 3 & Diet 4 & $\mathrm{SE}^{*}$ \\
\hline $\begin{array}{l}\text { Fat plus white fish meal premix } \\
\text { Fat used }(x 3 \cdot 3 \% \text { of premix, } 1 \cdot 5 \% \\
\text { of total diet })\end{array}$ & Anchovy & Anchovy & Anchovy & Tallow & - \\
\hline $\begin{array}{l}\text { Period for oxidation at } 15^{\circ} \text { in air } \\
\text { (months) }\end{array}$ & None & $3-4 \frac{1}{2}$ & 3 & None & - \\
\hline $\begin{array}{l}\text { Peroxide value ( } \mu \text { moles } / g) \text { of } \\
\text { extractable lipid ( } 19.1 \% \text { of premix, } \\
2.2 \% \text { of total diet) when mixed into } \\
\text { the diet }\end{array}$ & 13 & Iro $\rightarrow 60$ & I 10 & 2 & 一 \\
\hline \multicolumn{6}{|l|}{ Whole diet } \\
\hline $\begin{array}{l}\text { Storage time at } 15^{\circ} \text { in air between } \\
\text { mixing with fish meal premix } \\
\text { and feeding (months) }\end{array}$ & $3-4 \frac{1}{2}$ & None & $3-4 \frac{1}{2}$ & None & 一 \\
\hline $\begin{array}{l}\text { Peroxide value }(\mu \text { moles } / g) \text { of total } \\
\text { extractable lipids }(6 \cdot 85 \% \text { of diet }) \\
\text { over feeding period }\end{array}$ & $8-10$ & $48-27$ & $17-13$ & 3 & 一 \\
\hline \multicolumn{6}{|l|}{$\begin{array}{l}\text { Response of turkeys (three cages of } \\
\text { seven birds/treatment) from } \\
\text { day-old to } 6 \text { weeks): }\end{array}$} \\
\hline Live-weight gain (g/poult) & 868 & 838 & 836 & 890 & \pm 24 \\
\hline Food intake (g/poult) & 1720 & 1670 & 1680 & 1750 & \pm 48 \\
\hline Food conversion ratio & $\mathbf{r} \cdot 98$ & 1.99 & $2 \cdot 03$ & $\mathrm{r} \cdot 97$ & \pm 0.028 \\
\hline \multicolumn{6}{|l|}{ Measurements at slaughter: } \\
\hline Liver wt (as \% body-wt) & I.73 & $1 \cdot 73$ & $1 \cdot 72$ & $x \cdot 74$ & \pm 0.019 \\
\hline Vitamin $A$ in liver $\uparrow$ (i.u./liver) & 800 & $55^{\circ}$ & 670 & 1050 & \pm 60 \\
\hline Asp.T levelf (International Units) & 179 & 169 & 169 & 145 & $\pm 10 \cdot 6$ \\
\hline Al.T levelf (International Units) & $4 \cdot 4$ & 3.7 & $4 \cdot 0$ & $4 \cdot 0$ & \pm 0.25 \\
\hline
\end{tabular}

* Standard errors of treatment means. These were always calculated from cage means and were based on 8 degrees of freedom. In an analysis of variance, only the vitamin A contents of the livers were found significantly affected by treatment, with those for diet 4 higher than all the others $(P<0.05)$ and for diet $\mathrm{I}$ higher than for diet $2(P<0.05)$.

$\uparrow$ Mean of six control poults at day-old was $230( \pm 8)$ i.u./liver.

$\ddagger$ Asp.T, serum aspartate aminotransferase; Al. T, serum alanine aminotransferase.

Table 2. Average flavour ranking for the roasted turkey meat

$$
\text { (Preference for score: best }=\mathrm{I} \text {, worst }=4 \text { ) }
$$

Diet :

$$
\text { Sample no.... }
$$

I (fresh fish oil)

2 (oxidized fish oil)

3 (oxidized fish oil)

\begin{tabular}{|c|c|c|c|c|c|c|c|c|}
\hline \multicolumn{4}{|c|}{ Breast } & \multicolumn{4}{|c|}{ Leg } & \multirow[b]{2}{*}{ Average } \\
\hline I & 2 & I R* & $2 \mathrm{R} *$ & I & 2 & I R* & $2 \mathrm{R}^{*}$ & \\
\hline $2: 7$ & $4^{\circ} \circ$ & 4.0 & 3.9 & $3 \cdot 8$ & $4 \circ 0$ & 3.9 & $4^{\circ} 0$ & $3 \cdot 8$ \\
\hline $2 \cdot 5$ & $2 \cdot x$ & $2 \cdot 0$ & $2 \cdot 8$ & $I \cdot 8$ & $I \cdot 6$ & $2 \cdot 2$ & $2 \cdot 2$ & $2 \cdot I$ \\
\hline $2 \cdot 4$ & $2 \cdot 0$ & $1 \cdot 6$ & I.3 & $2 \cdot 9$ & I. 8 & $2 \cdot 1$ & $I \cdot 9$ & $2 \cdot 0$ \\
\hline $2 \cdot 4$ & $I \cdot 9$ & $2 \cdot 4$ & $2 \cdot 0$ & $\mathrm{I} \cdot 5$ & $2 \cdot 6$ & I 8 & $I \cdot 9$ & $2 \cdot 1$ \\
\hline
\end{tabular}

4 (beef fat control)
* Reheated sample. 


\section{DISCUSSION}

The anchovy oil-white fish meal mixture behaved like an oily fish meal in absorbing oxygen rapidly, after an induction period, with accompanying loss of unsaturation (Fig. r). The amount of oxygen absorbed corresponded to more than I mole of oxygen reacting and the fall in iodine value to the loss of about one double bond per mole of fatty acid present. But the highly unsaturated fatty acids with five and six double bonds per molecule characteristic of fish oils are known to disappear selectively when oils containing them are autoxidized (Jangaard, Ackman, Burgher \& Hughes, 1963), and the amount of oxidation recorded in our experiments must have destroyed virtually all of these reactive constituents of the oils. It is, in fact, difficult to feed partly oxidized fish oil to birds, because oxidation, once started, tends to proceed rapidly until all the most reactive acids have been destroyed.

Absorption of the amount of oxygen recorded for the anchovy oil-white fish meal mixture used in diets 2 and 3 would correspond, if all were converted into peroxide, to a theoretical pv of the order of $3000-4000 \mu \mathrm{moles} / \mathrm{g}$ oil, but the maximum figure reached was only 260 , and this for a brief period only. Subsequently the peroxide value fell, rapidly at first and then more slowly, as is commonly observed with commercial oily fish meals. The oxidation of the oil was accompanied by a fall of approximately $12 \%$ in the FDNB-available lysine value of the protein in the meal. This is similar to results with stored herring meal (Carpenter et al. 1963) and must reflect a loss in nutritional value of the material. However, the diets were designed to have some margin of safety in their protein content. When first incorporated in the basal diet, for feeding as diet no. 2, the lipid of the anchovy oil-white fish meal mixture had a pv of I I $\mu$ moles $/ g$, falling to 60 by the end of the 6 -week feeding period. With diet no. 3 , which was stored for 3 months before feeding, the peroxide content (recorded in Fig. 2 on the total dietary lipid basis) was lower, but more opportunity had been given for the peroxidized fish lipid to damage other constituents of the diet. Nevertheless, the turkey poults receiving these two diets remained healthy and grew well, though their weight gains appeared to be slightly (but not significantly) less than those of birds on the control beef fat diet.

Oxidation of the fresh anchovy oil-white fish meal mixture was considerably retarded when it was mixed with the basal diet to form diet no. I, presumably owing to protection by the cereals, and its pv did not increase (Fig. 2). Nevertheless, the mixture absorbed oxygen more than four times as rapidly as the basal diet alone (Fig. 1), indicating that in this diet an oxidizing fish oil was being given, though the pv of the extracted lipids remained low, stressing once more the limitations of the pv as a measure of lipid oxidation. Again, the turkeys remained healthy and grew well.

A difference between our experiments and those of Oldfield $e t$ al. (1963) was that our diets, containing only $\mathrm{r} \cdot 5 \%$ of added $(2 \cdot 2 \%$ of total) fish oil, were not oxidized appreciably during $24 \mathrm{~h}$ in the feeding troughs, even at $32^{\circ}$, whereas Oldfield's diets, containing $10 \%$ of added fish oil, oxidized under these conditions to a considerable extent and even fresh oils produced toxic effects.

As in the previous experiments with rats and chicks, the most sensitive indicator 
of the presence of oxidized fat in the diet proved to be a reduced storage of vitamin A in the liver but, since the diets were no more than adequate in their content of this vitamin the performances of all the groups were again considered satisfactory. It was previously reported that the effect of dietary peroxides on vitamin A storage in the liver was not due to destruction of the stabilized vitamin in the diet during storage (Lea et al. 1964), and this is confirmed in the experiments reported here, since the lowest storage of vitamin A occurred when the oxidized fish meal was mixed with the rest of the diet daily before feeding, i.e. with diet no. 2. Presumably destruction occurred during digestion and absorption, after the vitamin had been released from its protective matrix.

The mean Asp.T level, expressed in International Units, of all poults in this experiment was 164 . This figure is somewhat higher than the level of 88 (the published GOT value of ${ }^{1} 5^{6}$ converted into International Units) reported for normal poults at 6 weeks of age by Walter \& Jensen ( 1964 ), who associated elevated levels with muscular dystrophy. Though none of the poults in this experiment showed any signs of vitamin E deficiency such as muscular dystrophy or liver necrosis, it is to be noted that the level of Asp.T tended to increase with an increase in degree of unsaturation of the dietary lipids; i.e. it was highest on diet $\mathrm{I}$ and lowest on diet 4.

The effects of the fish oil on the flavour of the roasted meat seem of some practical relevance. In diet no. $\mathrm{I}$, some oxidation of the $2 \cdot 2 \%$ of total fish oil present $(\mathrm{I} \cdot 5 \%$ anchovy oil, $0.7 \%$ lipid of the white fish meal) occurred during storage, but most of the highly unsaturated fatty acids characteristic of the fish oils must have remained undamaged and the flavour of the roasted turkey meat was unanimously condemned as fishy. On the other hand, in diets 2 and 3 these polyunsaturated fatty acids must have been largely destroyed by oxidation and oxidative polymerization, and the turkeys raised on them gave meat as palatable as the controls raised on the beef fat diet, with no more than an occasional suggestion of slight fishiness. It may be recalled, for comparison, that in a previous investigation with hens the feeding of $1.4 \%$ of fish lipid as fresh or stored herring meal produced no detectable fishy taint in either flesh or eggs (Lea, Parr \& Carpenter, r960). Norwegian workers (Astrup, Hvidsten \& Aure, 1962) have observed a greater degree of tainting of pork when antioxidantstabilized herring meal was given to the pigs, as compared with ordinary herring meal, in which, presumably, the oil was much more severely oxidized.

We thank the Veterinary Investigation Centre, Cambridge, for post-mortem examination of the two sick birds, and Dr D. H. Shrimpton and Mrs I. W. Jennings for inspecting the carcasses of all the turkeys killed at the end of the experiment. 


\section{REFERENCES}

Astrup, H., Hvidsten, H. \& Aure, L. (1962). Acta polytech. scand. ser. 21, p. I02. Boyd, J. W., Douglas, T. A., Gould, C. M. \& Grimes, F. C. (1964). Vet. Rec. 76, 567.

Carpenter, K. J., Lea, C. H. \& Parr, L. J. (1963). Br. F. Nutr. 17, 151.

Carpenter, K. J., L'Estrange, J. L. \& Lea, C. H. (r 966). Proc. Nutr. Soc. 25, 25.

Jangaard, P. M., Ackman, R. G., Burgher, R. D. \& Hughes, M. L. (1963). F. Fish. Res. Bd Can. 20, no. I, p. 89 .

Laksesvela, B. (1961). Meld. SSF. January 1961, p. 7. Quoted in Nutr. Abstr. Rev. (1961), 31, 1434.

Lea, C. H. \& Hobson-Frohock, A. (1965). 7. Sci. Fd Agric. 16, I8.

Lea, C. H., Parr, L. J. \& Carpenter, K. J. (1960). Br. F. Nutr. I4, 91.

Lea, C. H., Parr, L. J., L'Estrange, J. L. \& Carpenter, K. J. (1964). Br. F. Nutr. 18, 369.

L'Estrange, J. L., Carpenter, K. J., Lea, C. H. \& Parr, L. J. (1965). Proc. Nutr. Soc. 24, xxxiii.

L'Estrange, J. L., Carpenter, K. J., Lea, C. H. \& Parr, L. J. (1966). Br. Y. Nutr. 20, i I3.

March, B. E., Biely, J., Claggett, F. E. \& 'Tarr, H. L. A. (ro62). Poult. Sci. 4r, 873 .

Mecchi, E. P., Pool, M. F., Behman, G. A., Hamachi, M. \& Klose, A. A. (1956). Poult. Sci. $35,1238$.

Oldfield, J. E., Sinnhuber, R. O. \& Rasheed, A. A. (r963). Y. Am. Oil Chem. Soc. 40, 357.

Rasheed, A. A., Oldfield, J. E., Kaufmes, J. \& Sinnhuber, R. O. (1963). \%. Nutr. 79, 323.

Sigma Chemical Company (1964). Tech. Bull. Sigma Chemical Co., St Louis, Mo., no. 505.

Täufel, K. \& Linow, F. (r964). Proc. Wld Fat Congr. Hamburg, p. 97.

Walter, E. D. \& Jensen, L. S. (1964). Poult. Sci. 43, 9 19. 